\section{UK insurers allowed to use genetic tests}

Britain has become the first country in the world to endorse the use of genetic testing to assess insurance premiums.

The government agreed last month that companies can use the results of tests for Huntingdon's Disease in assessing an individual's life insurance premiums. The decision follows an assessment by the UK Department of Health's Genetics and Insurance Committee (GAIC) that the current tests for the disease are reliable, and that "an abnormal result is associated with significant clinical effects and with an increased probability of a claim on a life insurance policy."

The announcement was immediately criticized by the National Consumer Council (NCC), which argued that individuals might choose not to have genetic tests in case it prevented them from being granted insurance.

"Simply grafting the new science of genotyping on to traditional insurance practices could lead to exclusion and the avoidance by patients of useful medical advances," says Anne Bradley, director of

\section{the council.}

But the Association for British Insurers $(\mathrm{ABI})$, which had earlier rejected government proposals for a moratorium on the use of genetic test data in assessing premiums, said that it was "pleased" at the committee's decision. Chairman John Durrant says that one benefit is that those with a family history of Huntington's Disease, but with a negative test result, would not be asked to pay more for life insurance; at present, he points out, many of those who have a history of such genetic disorders have difficulty in obtaining insurance as a result.

The association is now awaiting judgements from the committee on the possible use of six further tests-ranging from early onset Alzheimer's Disease to heredity breast cancer. Mary Francis, the association's director, emphasizes that insurers "do not, and will not, ask someone to take a genetic test as a condition of obtaining insurance." But where individuals have al ready been tested as part of their medical care, there is nothing to prevent insurance companies using that infor- mation.

The $A B I$ has already agreed to stop using any genetic test if investigation by the GAIC into its reliability and relevance finds insufficient evidence to justify its use. In such cases, the industry has agreed to reassess individual insurance premiums retrospectively.

This is not enough for the NCC, which argues that, while not excluding the possible future use of genetic tests for insurance purposes, the current ways in which premiums are calculated are insufficient to protect individuals from bearing an unfair burden of the costs. "When genies are let out of bottles, the world changes irrevocably," says Bradley. "Genetic testing is such a genie."

The Genetic Interest Group, a consortium of charities dedicated to research in individual genetic disease, is more laid back. "Given the previous importance attached to family history in cases of Huntingdon's Disease and similar monogenic diseases [in assessing premiums], this issue seems to have been overblown," says campaign director John Gillott.

David Dickson, London

\title{
South African village prepares for first HIV vaccine trial...
}

Despite the South African president's belief that human immunodeficiency virus (HIV) does not cause AIDS, the country's Medical Research Council (MRC) has announced that it will begin trials of an HIV vaccine in February 2001.

Ongoing preparations for such a trial in the rural South African village of Hlabisa emphasize the complexities of gearing up for a large efficacy study in the epicenter of the country's AIDS epidemic. After nearly two years of educating tribes and gaining their consent, researchers predict the site will be ready for a large-scale study by the end of next year-most probably sooner than large quantities of the vaccine will be ready for testing.

The Venezuelan equine encephalitis (VEE) virus vaccine to be tested is being produced at Greer Laboratories, North Carolina, on behalf of Alphavax, a company formed two years ago by University of North Carolina researchers. The South African AIDS Vaccine Initiative (SAAVI), in conjunction with the US National Institute of
Allergy and Infectious Diseases (NIAID), has teamed with the International AIDS Vaccine Initiative (IAVI) to fund development. Quantities sufficient for phase I trials in the US and South Africa should be ready by the end the year, and phase III trials are scheduled for completion by 2005 .

Developed with the help of the US Army, the vaccine uses an attenuated form of VEE virus inserted with genes selected from

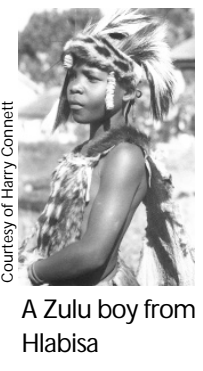

means a different kind of preparation for the large trials," IAVI President Seth Berkley told Nature Medicine. "The worst thing we could do is have an exciting candidate and then say, 'Ah, how do we move to the next stage.' "

Because vaccines have potential prophylactic rather than therapeutic value, informed consent is a delicate issue for any vaccine trial, even in Westernized countries. Testing subtype $C$ isolates of South African seroconverters, making it the first vaccine specific for clade $\mathrm{C}$-the most prevalent HIV-1 subtype in Africa-to enter trials. According to Robert OImsted, vice president of research at AlphaVax, the biological properties of the VEE virus make it an attractive AIDS vaccine delivery system because it targets lymphoid tissue.

The trial is expected to follow the type of fast-track course outlined in IAVI's Scientific Blueprint 2000: Accelerating Global Efforts in AIDS Vaccine Development. "We would really like to dramatically shorten timelines and that an AIDS vaccine in rural South Africa requires the added challenge of gaining the trust of tribal leaders and winning their support. Social interaction and decision-making in Zulu culture is built on a hierarchical concept of togetherness called 'ubuntu'.

For the past three years, the South African MRC has been studying how such solidarity influences the highly individualized activity of consenting to a vaccine study. Researchers have learned that laying the groundwork for a vaccine trial can succeed only by going to tribal leaders first and getting their 
stamp of approval.

Primarily because of its high incidence rate- $40 \%$ in pregnant womenHlabisa, four hours northeast of Durban, has been chosen as a site for phase II and III trials of the VEE vaccine. The MRC gained access to Hlabisa villagers only after months of public-relations building with the chief of the tribal area, Inkosi Hlabisa, and his 25 'idunas', or cluster leaders, each of whom presides over 150 families. The Hlabisa chief eventually called together a community gathering of about 6,000 people to explain his reasons for supporting the MRC's research. "The head men cannot give consent for anybody's participation, but without their approval it would be difficult if not impossible to work in their communities," explains Salim Karim, MRC director of HIV Prevention and Vaccination.

For the past 20 months, health workers have been recruiting and training young community educators to take vaccine trial information to the 12 clusters that make up the Hlabisa tribal area. On weekends, cluster leaders host community meetings at which the educators demonstrate how blood is drawn and medical histories are obtained. Tribal songs and dances also are used to spread the HIV-prevention message.

The level of vaccine preparedness in Hlabisa has been "excellent," says Steve Self, senior biostatistician for the new international HIV Vaccine Trials Network, and professor of biostatistics at the University of Washington (Nature Med. 6, 488; 2000). "The kind of work going on there will have a huge impact on speeding up the process." So far, efforts to identify and educate potential trial volunteers seem to be paying off. Working out of a trailer and a two-room research clinic surrounded by a security fence, field site manager Janet Frolich says participation in the vaccine preparedness trial has been high. Although results are not yet published, more than $95 \%$ of those surveyed so far agreed to participate in the study, and about $70 \%$ have agreed to be tested.

Despite ongoing research, including the recent completion of a large randomized STD intervention study that provided condoms and drugs for symptomatic patients visiting local health clinics, HIV infection rates have continued to rise in Hlabisa. Last year, 'detuned' assay surveillance revealed a double-digit annual infection rate. Such

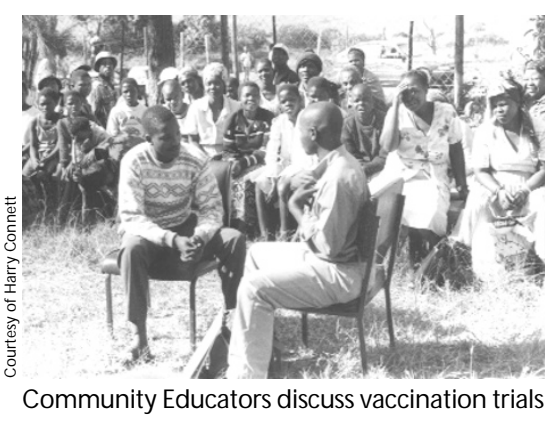

a high incidence rate will reduce the necessary sample size to around 4,000, says Salim Abdool Karim, director of HIV Prevention and Vaccine research for the MRC.

Although the vaccine preparedness study has received no funding from SAAVI or IAVI-NIAID is the primary supporter-work in Hlabisa has progressed so well that Karim expects to have the site ready for an efficacy trail by the end of 2001. "I don't expect there will be a phase III vaccine available by then," he says, "but we should be ready to go with it."

Harold Connett, Atlanta

Although more than 60 phase I/II trials of 30 candidate human immunodeficiency virus (HIV) vaccines have been conducted worldwide, none has so far been dedicated to clade $\mathrm{C}$, the predominant subtype in South Africa, which has the largest number of infected people in the world, 4.2 million. AlphaVax's VEE vaccine will be the first to do so (see main story).

In fact, only a fraction of the money spent on HIV vaccine development worldwide-\$10-25 million out of $\$ 300$-350 million-is invested in developing vaccines against subtypes of virus that affect most of the world's HIV patients, according to the latest report by the World Bank (http://www.worldbank.org/poverty/wdrpoverty/report/index.htm). Moreover, the amount spent on HIV vaccine research is substantially less than the $\$ 2$ billion spent on $R \& D$ for drug treatments aimed at the three million people with HIV/AIDS in industrialized countries.

K.B.

\section{... while government causes confusion}

In addition to the many problems that surround the trial of any vaccine against HIV/AIDS, those sponsoring the VEE trial face the additional obstacle that the South African population is receiving mixed messages from its leaders.

Speaking publicly last month, president Thabo Mebki, who has angered many western scientists with his views that HIV does not cause AIDS, said that AIDS is acquired immune defense syndrome, and a syndrome can not be caused by a virus. He repeated his views-that HIV is a passenger virus and that the disease is caused by other factors-when addressing the parliamentary caucus of the African National Congress (ANC). He has now promised to remove himself from the debate to avoid further confusion.

$\mathrm{He}$ also told them that he and the government are the subject of propaganda by the American $\mathrm{ClA}$ and large pharmaceutical companies, partially because he has questioned the link between the virus and AIDS. But in spite of Mbeki's statements, the government is launching a R2 billion media campaign to clear up confusion over its stance on the issue. The campaign will be based on the premise that HIV is responsible for the disease.

This public relations exercise comes amid revelations that Members of Parliament benefit from a medical aid scheme, Parmed, that pays two thirds of the cost of anti-HIV therapy and provides AZT to pregnant M Ps and those that have been raped. This is at odds with the government's policy for ordinary citizens which states that it is illegal to give AZT to rape victims, and with its charges that the drug is toxic. It has consistently refused to buy the drug at a $70 \%$ reduced price for use in mother-to-child transmission, and last month, Health Minister Manto Tshabalala-M simang repeated her message to parliament that the government simply can not afford AIDS drugs for its people

Meanwhile, a meeting of the country's insurance experts, which also took place last month, stressed the implications of the disease for the economy. Rob Dorrington, professor of actuarial studies at the University of Capetown, told attendees that $13 \%$ of the country's 42 milIion people would be infected by the end of this year, and that life expectancy will drop to 41 years by 2010 , by which time $45 \%$ of adults will be infected.

Karen Birmingham, London 